\title{
Evaluation of Hepatoprotective activity of Eriocaulon quinquangulare in vitro using porcine liver slices against ethanol induced liver toxicity and free radical scavenging capacity
}

Chamira Dilanka Fernando ${ }^{1,2}$ and Preethi Soysa ${ }^{1 *}$

\begin{abstract}
Background: Production of reactive oxygen species is a common cause in alcohol induced liver diseases. Decoction prepared from the whole plant of Eriocaulon quinquingulare is prescribed to treat liver disorders. The aim of this study was to investigate the hepatoprotective activity and antioxidant capacity of the water extract of $E$. quinquangulare in vitro.

Method: The aqueous extract of the whole plant of $E$. quinquangulare (AEQ) was investigated for its phytochemical constituents, antioxidant and membrane stabilization properties in-vitro. The antioxidant activities of AEQ were investigated using 1,1-Diphenyl-2-picrylhydrazyl (DPPH), hydroxyl radical, nitric oxide scavenging and ferric reducing antioxidant power (FRAP) assays. Membrane stabilizing effect of the extract was determined by hypotonic solution induced human erythrocyte hemolytic assay (HEHA). Further, hepatoprotective activity against ethanol induced hepatotoxicity was carried out using porcine liver slices.

Results: The total phenolics and flavonoids were $10.3 \pm 1.6 \mathrm{w} / \mathrm{w} \%$ gallic acid equivalents and $45.6 \pm 3.8 \mathrm{w} / \mathrm{w} \%$ (-)-epigallocatechin gallate equivalents respectively. The values of $\mathrm{EC}_{50}$ for $\mathrm{DPPH}$, hydroxyl radical and nitric oxide scavenging assays were $37.2 \pm 1.7 \mu \mathrm{g} / \mathrm{ml}, 170.5 \pm 6.6 \mu \mathrm{g} / \mathrm{ml}$ and $31.8 \pm 2.2 \mu \mathrm{g} / \mathrm{ml}$ respectively. The reducing capability of AEQ was $6.9 \pm 0.2 \mathrm{w} / \mathrm{w} \% \mathrm{~L}$-ascorbic acid equivalents in the FRAP assay. For hypotonic solution induced HEHA, the $\mathrm{IC}_{50}$ was $1.79 \pm 0.04 \mathrm{mg} / \mathrm{ml}$. A significant decrease $(p<0.05)$ was observed in ALT, AST and LDH release from the liver slices treated with AEQ compared to the ethanol treated liver slices. A significant reduction in lipid peroxidation $(p<0.05)$ was also observed in liver slices treated with the plant extract compared to that of the ethanol treated liver slices.
\end{abstract}

Conclusions: The results suggest AEQ possess hepatoprotective activity against ethanol induced liver toxicity of porcine liver slices which can be attributed to antioxidant properties and membrane stabilizing effects caused by the plant material.

Keywords: Antioxidant properties, Eriocaulon quinquangulare, Hepatoprotective activity, Membrane stabilization activity

\footnotetext{
* Correspondence: indunilsree@gmail.com

'Department of Biochemistry \& Molecular Biology, Faculty of Medicine,

University of Colombo, Kynsey Road, Colombo 08, Sri Lanka

Full list of author information is available at the end of the article
} 


\section{Background}

Reactive oxygen (ROS) and nitrogen species (RNS) are produced as byproducts during cellular metabolism or exposure to environment chemicals and radiation. Over production of ROS and RNS cause oxidative damage to biomolecules, provoke immune response, activate oncogenes and hasten the ageing process [1]. Chronic alcoholism leads to the development of alcoholic liver disease and is a major health problem in the society. Metabolism of ethanol occurs in the liver, catalyzed by alcohol dehydrogenase, aldehyde dehydrogenase (ALDH), cytochrome P450 2E1 (CYP2E1), and catalase enzymes [2]. These mechanisms result in the decrease of $\mathrm{NAD}^{+} / \mathrm{NADH}$ redox ratio and depletion of reduced glutathione (GSH) leading to oxidative stress $[3,4]$. Several studies have shown that antioxidants including plant extracts protect against ethanol induced hepatotoxicity by inhibiting lipid peroxidation and enhancing antioxidant enzyme activity [5]. Use of plant derived drugs in medical practice has shown that they are relatively non-toxic, safe and free from serious side effects [6].

Eriocaulon quinquangulare (Family: Eriocaulaceae) locally known as "Heen kokmota" is a slender annual tuft. This monocotyledonous plant is distributed in lowlands in Sri Lanka [7]. The total plant of Eriocaulon quinquangulare prepared as decoction is used to treat patients suffering from liver disorders, jaundice and splenomegaly in Sri Lanka [8].

The present study was carried out to determine the phytochemical composition, antioxidant, membrane stabilization and hepatoprotective activities of aqueous extract of E. quinquangulare (AEQ) to evaluate the scientific base of its application as a hepatoprotective drug.

\section{Methods}

\section{Chemicals and equipment}

The chemicals gallic acid, Folin ciocalteu reagent, trichloroacetic acid, sodium salicylate and ethylenediamine tetra acetic acid (EDTA) were purchased from Sigma Chemicals Co. (P.O. Box 14508, St. Louis, MO 63178 USA). 1,1-Diphenyl-2-picrylhydrazyl (DPPH) free radical, (-)-epigallocatechin gallate, aluminium chloride and sulfanilamide were purchased by Fluka (Flukachemie GmbH, CH-9471 Buchs). L-ascorbic acid, hydrogen peroxide, N-(1-naphthyl)-ethylenediamine dihydrochloride and ethanol were purchased from BDH Chemicals (BDH Chemicals Ltd, Poole, England). Ferric chloride, potassium ferricyanide and sodium nitrite were purchased from Riedel De Haen Ag, Wunstorfer Strasse 40, SEELZE1, D3016, Germany.

Lactate dehydrogenase (LDH) enzyme assay kit was purchased from DiaSys (Alte Strasse 9, 65558, Holzheim, Germany). Alanine transaminase (ALT) and Aspartate transaminase (AST) enzyme assay kits were purchased from POINTE, SCIENTIFIC, INC (5449 Research Drive, Canton MI 48188, USA).

\section{Plant material}

The whole plant of Ericaulon quinquangulare (Heen Kokmota) was collected from Kalutara District. This plant material was identified and confirmed by Department of Botany, Bandaranaike Memorial Ayurvedic Research Institute, Nawinna, Sri Lanka. A voucher specimen of the plant was deposited at the herbarium of the above Institute (acc number: 980c).

\section{Preparation of the decoction}

Decoction from total plant of Eriocaulon quinquangulare was prepared according to a procedure followed by Ayurvedic practitioners of Sri Lanka [9]. Plant material was washed with deionized water and dried to achieve a constant weight at room temperature. Dried material was cut into small pieces and ground to a fine powder. A weight of $30 \mathrm{~g}$ was boiled with $800 \mathrm{ml}$ of deionized water until its volume gets reduced to $100 \mathrm{ml}\left(1 / 8^{\text {th }}\right.$ of the original volume). The decoction was sonicated and filtered. The filtrate was centrifuged (2000 rpm, $10 \mathrm{~min}$ ). The supernatant was freeze dried and stored at $-20{ }^{\circ} \mathrm{C}$ in sterile tubes until further use. The yield of the lyophilized powder was calculated as a percentage of the dry weight. The lyophilized powder was dissolved in deionized water or buffer for the experiments and concentration of the treated sample was calculated as $\mu \mathrm{g} / \mathrm{ml}$ or $\mathrm{mg} / \mathrm{ml}$ of the lyophilized sample.

\section{Phytochemical constituents}

The phytochemicals present in AEQ was determined according to a previously published method [10]. The extract was screened for carbohydrates, tannins, phenols, phlobatannins, amino acids and proteins, saponins, flavonoids, sterols, terpenoids, cardiac glycosides, alkaloids, quinones and oxalates.

\section{Determination of total phenolic content}

Total phenolic content of AEQ was determined by Folin Ciocalteu method [11]. Calibration curve was constructed using gallic acid standards and the total phenolic content was reported as w/w\% gallic acid equivalents (GAE).

\section{Determination of flavonoid content}

The flavonoid content was quantified by the aluminium chloride colorimetric assay [11]. Calibration curve was plotted using (-)-epigallocatechin gallate (EGCG) standards and flavonoid content was reported as w/w\% EGCG equivalents. 


\section{1,1-Diphenyl-2-picrylhydrazyl (DPPH) free radical scavenging activity}

Free radical scavenging ability of AEQ prepared was assessed by DPPH radical scavenging method with slight modifications [11]. DPPH reagent prepared in absolute ethanol $(100 \mu \mathrm{M}, 750 \mu \mathrm{l})$ was added to test sample $(250 \mu \mathrm{l})$ and the mixture was allowed to stand for $30 \mathrm{~min}$ in the dark. Absorbance was measured at $517 \mathrm{~nm}$. Percentage inhibition was calculated according to Eq. 1

$$
\begin{aligned}
& \% \text { Inhibition } \\
& =\frac{\text { Absorbance of control - Absorbance of sample X } 100}{\text { Absorbance of control }}
\end{aligned}
$$

L-Ascorbic acid was used as the positive control. The effective concentration needed to scavenge $\mathrm{DPPH}$ free radical by $50 \%\left(\mathrm{EC}_{50}\right)$ was calculated by regression analysis of the dose response curve plotted between percentage inhibition versus concentration of the test samples and the positive control.

\section{Hydroxyl radical scavenging activity}

Hydroxyl radical scavenging activity was measured based on the competition between deoxyribose and the test compound (the plant extract) to react with hydroxyl radicals generated from $\mathrm{Fe}^{2+} /$ Ascorbate/EDTA/ $\mathrm{H}_{2} \mathrm{O}_{2}$ system according to the procedure as previously described with slight modifications [12]. Gallic acid was used as the positive control. The percentage scavenging of hydroxyl radical for AEQ and the positive control was calculated according to equation $1 . \mathrm{EC}_{50}$ was calculated as described previously.

\section{Nitric oxide radical (NO) scavenging activity}

NO was generated from sodium nitroprusside (SNP) and NO scavenging activity of AEQ was measured based on Griess-Ilosvay reaction with slight modification [13]. The interference from the plant extract with the pink chromophore formed was minimized by background subtraction of absorbance for respective concentrations. L-Ascorbic acid was used as the positive control. The percentage scavenging of $\mathrm{NO}$ for $\mathrm{AEQ}$ and the positive control was calculated according to equation $1 . \mathrm{EC}_{50}$ was calculated as described previously.

\section{Ferric reducing antioxidant power (FRAP) assay}

The ferric ion reducing power of AEQ was determined according to a method described previously [14]. Lascorbic acid was used as the positive control. Dose response curve was plotted between the absorbance versus concentrations of plant extract or positive control. The ferric reducing antioxidant power of the decoction was expressed as w/w\% L-ascorbic acid equivalents.

\section{Porcine liver tissue collection}

Porcine liver tissue of either sex was obtained from the registered slaughter house in Dematagoda, Sri Lanka with permission obtained from the chief municipal veterinary surgeon (Refer the Section III.24 of Additional file 1 regarding ethical approval).

A sample of liver tissue without distinction of lobes was excised using sterile scalpel blades and transferred immediately into ice cold sterile Krebs Ringers-4-(2hydroxyethyl)-1-piperazineethanesulfonic acid (HEPES) buffer (KRHB) and transported to the laboratory on the day of the experiment within $5 \mathrm{~min}$ in an ice bath.

\section{Preparation of medium}

The buffer (KRHB) composition includes HEPES (2.5 mM), $\mathrm{NaCl}(118 \mathrm{mM}), \mathrm{KCl}(2.85 \mathrm{mM}), \mathrm{CaCl}_{2}$ (2.5 mM), $\mathrm{KH}_{2} \mathrm{PO}_{4}(1.5 \mathrm{mM}), \mathrm{MgSO}_{4}(1.18 \mathrm{mM})$ and glucose $(4.0 \mathrm{mM})$. The $\mathrm{pH}$ was adjusted to 7.4 by $1 \mathrm{~N}$ $\mathrm{NaOH}$. The medium was autoclaved for sterilization.

\section{Hepatoprotective activity of $E$. quinquangulare decoction in vitro}

Hepatoprotective activity of AEQ was evaluated according to a method published previously using porcine liver tissue obtained from slaughter house [15]. Fresh, cleaned tissue was cut into thin slices (20-25 mg) and $100 \mathrm{mg}$ was transferred into clean sample collection glass vials filled with KRHB. Vials were capped and pre-incubated for $30 \mathrm{~min}$ in a shaker water bath at $37^{\circ} \mathrm{C}$. Liver slices were drained carefully and transferred into separate vials with different concentrations of AEQ dissolved in KRHB (400, 1000 and $2000 \mu \mathrm{g} / \mathrm{ml})$, co-exposed with ethanol (5 M) and incubated at $37^{\circ} \mathrm{C}$ for $2 \mathrm{~h}$. The final volume was adjusted to $3.0 \mathrm{ml}$ with KRHB. Tissues were exposed to the plant extract in the absence of ethanol to assess any hepatotoxic effect induced by the plant extract itself. A control was carried out in KRHB (3.0 ml). Ethanol (5 M) was used to induce hepatotoxicity as reported in a previous study [15]. After the incubation period, the spent media were collected and the liver slices were homogenized at $4{ }^{\circ} \mathrm{C}$. The homogenates were sonicated for 4 seconds and centrifuged at $4{ }^{\circ} \mathrm{C}$. The supernatants and the media obtained from post incubation of tissues were assayed for alanine transaminase (ALT), aspartate transaminase (AST) and lactate dehydrogenase (LDH). The percentage cytotoxicity was calculated using Eq. 2

The percentage cytotoxicity

$$
=\frac{\text { Enzyme activity in the medium }}{\text { Total Enzyme activity }} \times 100 \%
$$

Where Total Enzyme activity = Enzyme activity in the medium + Enzyme activity in the tissue homogenate, 
Medium = Medium used for the incubation of liver tissue

The tissue homogenates were also assayed for total protein content and lipid peroxides formed [16, 17]. Standard curves were plotted using bovine serum albumin (BSA) and 1,1,3,3-tetraethoxypropane (TEP) standards respectively and amount of lipid peroxides formed was expressed as micrograms of malondialdehyde (MDA) equivalents formed per gram of protein.

\section{Membrane stabilization activity}

The membrane stabilization activity of AEQ was determined using hypotonic solution induced human erythrocyte hemolytic assay (HEHA) according to the procedure described previously with slight modifications [18]. Fresh blood (5 ml) was collected and transferred to centrifuge tubes. The tubes were centrifuged at $2500 \mathrm{rpm}$ for $5 \mathrm{~min}$ and the supernatant was removed. The cell suspension was washed 3-4 times with isotonic buffer (154 mM sodium chloride in $10 \mathrm{mM}$ sodium phosphate buffer, $\mathrm{pH}$ 7.4) until the supernatant appeared clear. The volume of blood was measured and reconstituted as $40 \% \mathrm{v} / \mathrm{v}$ suspension with isotonic buffer. Human erythrocyte suspension $(40 \% \mathrm{v} / \mathrm{v}, 50 \mu \mathrm{l})$ was mixed with hypotonic buffer (50 mM sodium chloride in $10 \mathrm{mM}$ sodium phosphate buffer, $\mathrm{pH} 7.4,1.0 \mathrm{ml}$ ) and plant extract prepared in isotonic buffer $(100 \mu \mathrm{l})$. The samples were incubated for $20 \mathrm{~min}$ at room temperature followed by centrifugation ( $5000 \mathrm{rpm}, 5 \mathrm{~min}$ ). The absorbance of the supernatant was measured at $540 \mathrm{~nm}$. Appropriate samples were constructed to measure background interferences caused by the plant extract and this reading was subtracted from the original readings. Sodium salicylate was used as the positive control. Percentage inhibition of hemolysis caused by AEQ and sodium salicylate was measured according to Eq. 3

$$
\begin{aligned}
& \text { \% Inhibition of hemolysis } \\
& =\frac{\text { Absorbance of control - Absorbance of sample X } 100}{\text { Absorbance of control }}
\end{aligned}
$$

The effective concentration needed to inhibit the lysis of human erythrocytes by $50 \%$ compared to the control $\left(\mathrm{IC}_{50}\right)$ was calculated by regression analysis of the dose response curves.

\section{Statistical analysis}

Triplicate measurements were obtained for each experiment unless otherwise specified. Students $T$ test was performed for statistical analysis and results are presented as mean \pm standard deviation (Mean \pm SD). Value of $p<0.05$ was considered as significant. Regression analysis and statistical analysis were carried out using
Microsoft Excel. Calibration curves of the standards were considered as linear if $\mathrm{R}^{2}>0.99$. $\mathrm{EC}_{50}$ values were calculated from either linear or logarithmic dose response curves where $R^{2}>0.90$.

\section{Results and discussion}

Extraction yield, phytochemical constituents, phenolic and flavonoid contents

Extraction yield obtained for the whole plant extract of Eriocaulon quinquangulare was $4.33 \%$ as a percentage of dry weight. Results obtained for qualitative screening of phytochemicals in AEQ reveal that carbohydrates, tannins, phenols, phlobatannins, saponins, flavonoids and quinones were present in the extract where as sterols, terpenoids, amino acids and proteins, cardiac glycosides, alkaloids and oxalates were absent. Dietary polyphenolic compounds help to restore the balance between the natural antioxidants and free radicals by enhancing the activity of natural antioxidant enzymes such as superoxide dismutase (SOD), glutathione peroxidase (GPx), glutathione reductase (GR), glutathione-S-transferase (GST) and by direct scavenging of free radicals [19]. The total phenolic content of AEQ was $10.3 \pm 1.6 \mathrm{w} / \mathrm{w} \%$ GAE (Table 1). Studies conducted with the water extract of Eriocaulon sexangulare $\mathrm{L}$. which belong to the same family, has yielded a total phenolic content of $88.62 \pm 0.91 \mu \mathrm{g}$ Catechin equivalents/mg which is lower compared to AEQ [20]. Flavonoids as plant derived antioxidants exhibit antimutagenic and free-radical scavenging activities. Several flavonoids namely catechin, apigenin, quercetin, naringenin, rutin, and venoruton are reported for their hapatoprotective activities [21]. Aluminium chloride colorimetric assay for flavonoids yielded total flavonoid content of $45.6 \pm$ $3.8 \mathrm{w} / \mathrm{w} \%(-)$-epigallocatechin gallate (EGCG) equivalents for AEQ (Table 1) indicating that the plant extract is abundant in flavonoids which can exert health benefits. Studies conducted with water extract of Eriocaulon sexangulare has yielded a total flavonoid content of $9.57 \pm 0.25 \mu \mathrm{g}$ Rutin equivalents/mg compared to AEQ [20].

\section{Antioxidant capacity}

Oxidative stress is caused due to a variety of endogenous ROS/RNS produced during metabolic processes including ethanol metabolism and is believed to contribute significantly in the development of a number of diseases $[3,4,22]$. Therefore total antioxidant capacity of the decoction prepared was evaluated against

Table 1 Phytochemical composition of AEQ

\begin{tabular}{ll}
\hline Experiment & AEQ $(n=3)$ \\
\hline Phenolic content (w/w\% GAE) & $10.3 \pm 1.6$ \\
Flavonoid content (w/w \% EGCG equivalents) & $45.6 \pm 3.8$ \\
\hline
\end{tabular}


different radical systems which include DPPH, hydroxyl and nitric oxide as well as the ability to reduce ferric ions to achieve better understanding of the specific activities possessed by AEQ.

The hydrogen donating ability of the plant extract was determined by DPPH free radical. The free radical which is centered on nitrogen atom which is being delocalized within the aromatic system gives a characteristic purple colour measured around $517 \mathrm{~nm}$. In the presence of hydrogen donors (free radical scavengers), $\mathrm{DPPH}$ reacts with these hydrogen atoms and forms a stable product 1,1-Diphenyl-2-picrylhydrazine resulting in a colour change from purple to yellow [23]. In the current study $\mathrm{AEQ}$ exhibited $\mathrm{EC}_{50}$ value at a concentration of $37.2 \pm 1.7 \mu \mathrm{g} / \mathrm{ml}$ for DPPH assay which is higher than LAscorbic acid $(3.3 \pm 0.3 \mu \mathrm{g} / \mathrm{ml})$ (Fig. 1). However AEQ demonstrated higher hydrogen donating ability than Eriocaulon sexangulare L. extract for DPPH radical scavenging assay $\left(\mathrm{EC}_{50}>2000 \mu \mathrm{g} / \mathrm{ml}\right)[20]$.

Hydroxyl radical is an extremely reactive free radical formed in biological systems which can initiate lipid peroxidation of the cell membrane. Hydrogen peroxide generates hydroxyl radicals due to the catalysis by Iron (II). The hydroxyl radicals attack deoxyribose that eventually results in the formation of thiobarbituric acid reacting substances (TBARS) which couples with thiobarbituric acid (TBA) on heating to generate a pink-coloured product [12]. In the present study, AEQ demonstrated an $\mathrm{EC}_{50}$ value of $170.5 \pm 6.6 \mu \mathrm{g} / \mathrm{ml}$ compared to gallic acid which showed an $\mathrm{EC}_{50}$ value of $27.7 \pm 4.1 \mu \mathrm{g} / \mathrm{ml}$ (Table 2). The results obtained indicate the potential of the plant extract to prevent the degradation of deoxyribose in the presence of hydroxyl radicals in a dose dependent manner (Fig. 2).
Nitric oxide is a small molecule that contains one unpaired electron. It is generated in biological systems by $\mathrm{NADPH}$-dependent nitric oxide synthases. It acts as an important oxidative biological signaling molecule in a variety of physiological processes such as regulation of blood pressure and immune response, defense mechanism against pathogens, smooth muscle relaxation and neural signal transmission [24]. Overproduction of NO may occur when the generation of nitrogen species supersedes the ability of the biological system to neutralize and eliminate them. Increased levels of NO may lead to nitrosylation reactions that can alter the structure of protein and inhibit their function. When super oxide reacts with $\mathrm{NO}$, it produces strong oxidant molecule peroxynitrite ion $\left(\mathrm{ONOO}^{-}\right)$, which causes DNA fragmentation and lipid peroxidation [25].

Nitric oxide generated spontaneously from sodium nitroprusside (SNP) in aqueous solution at physiological $\mathrm{pH}$ interacts with oxygen to produce nitrite ions which in turn reacts with Griess reagent forming an azo-dye. Nitric oxide scavengers compete with oxygen which leads to reduced production of nitrite ions. The $\mathrm{EC}_{50}$ values obtained were $31.8 \pm 2.2$ and $276.3 \pm 25.8 \mu \mathrm{g} / \mathrm{ml}$ for AEQ and L-Ascorbic acid respectively reflecting its high capacity to scavenge NO (Fig. 3).

FRAP can serve as an important indicator of potential antioxidant activity which involves the transformation of $\mathrm{Fe}^{3+}-\mathrm{Fe}^{2+}$ in the presence of the antioxidant resulting in the formation of a blue-green coloured complex [26]. The reduction capability of both the plant extract and Lascorbic acid increased with the concentration (Fig. 4). The reducing power of AEQ was found to be $6.9 \pm 0.2$ $\mathrm{w} / \mathrm{w} \% \mathrm{~L}$-ascorbic acid equivalents. The results obtained

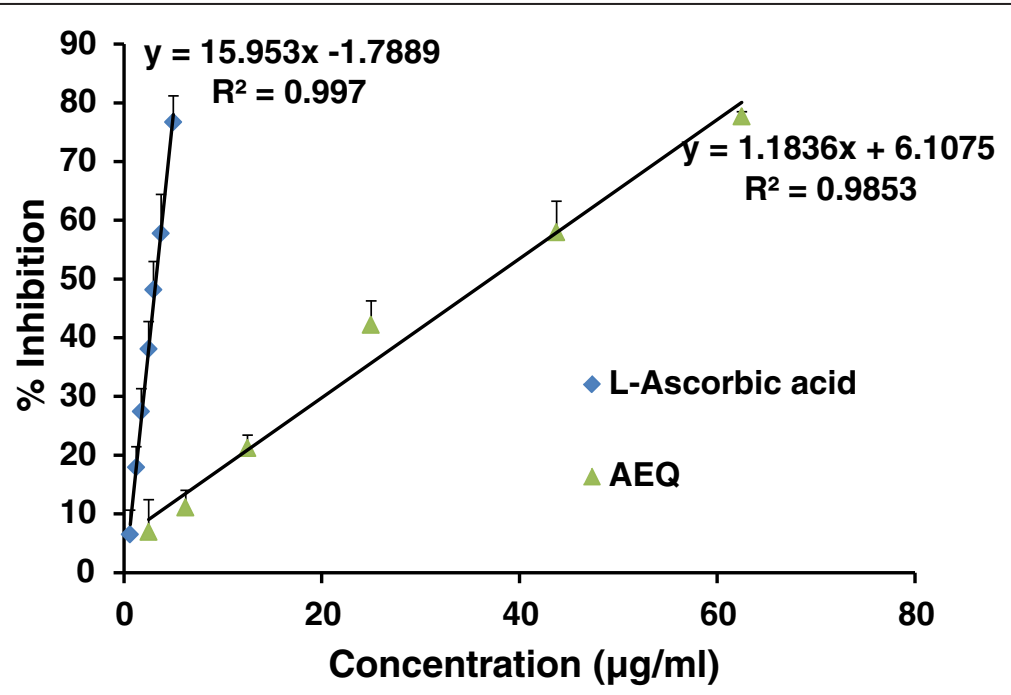

Fig 1 The dose response curves for percentage scavenging of DPPH by AEQ compared to L-Ascorbic acid. The results are presented as mean + SD for L-Ascorbic acid $(n=9)$ and AEQ $(n=3)$ 
Table 2 Antioxidant capacity of AEQ

\begin{tabular}{llll}
\hline Experiment & $\mathrm{EC}_{50}$ for AEQ $(n=3)$ & $\mathrm{EC}_{50}$ for positive control & \\
\hline DPPH radical scavenging activity & $37.2 \pm 1.7 \mu \mathrm{g} / \mathrm{ml}$ & L- Ascorbic acid & $3.3 \pm 0.3 \mu \mathrm{g} / \mathrm{ml}(n=9)$ \\
Hydroxyl radical scavenging activity & $170.5 \pm 6.6 \mu \mathrm{g} / \mathrm{ml}$ & Gallic acid & $27.7 \pm 4.1 \mu \mathrm{g} / \mathrm{ml}(n=9)$ \\
NO scavenging activity & $31.8 \pm 2.2 \mu \mathrm{g} / \mathrm{ml}$ & L-Ascorbic acid & $276.3 \pm 25.8 \mu \mathrm{g} / \mathrm{ml}(n=9)$ \\
FRAP assay (w/w \% L-Ascorbic acid equivalents) & $6.9 \pm 0.2(n=3)$ & & \\
\hline
\end{tabular}

in the experiments for antioxidant capacity of AEQ are presented in Table 2.

\section{Hepatoprotective activity of AEQ in-vitro}

Liver tissue obtained from slaughter house is a useful model to study hepatotoxicity of different substances in the organ level [27]. Further, liver slices have been successfully used for assaying hepatoprotective activity of curcumin [28], stem bark extract of Pterocarpus marsupium [29] and leaf extract of Atalantia ceylanica [15]. There is a similarity in liver specific metabolic activities between porcine and human liver cells [30]. Hence liver slices prepared from fresh porcine liver obtained from the slaughter house were used in this study.

Trial experiments were performed to find the optimum conditions needed and it was found that the minimum concentration of ethanol and exposure time required to induce liver damage was $5 \mathrm{M}$ and $2 \mathrm{~h}$ respectively. Ethanol induced toxicity was assessed by leakage of AST, ALT, and LDH enzymes to the medium which indicates the loss of functional integrity of the cell membrane [31]. Percentage AST, ALT, and LDH released in liver slices treated with ethanol $(5 \mathrm{M})$ for $2 \mathrm{~h}$ were $70.4 \%, 71.3 \%$ and $53.1 \%$ and for untreated liver slices (negative control), the values were $25.0 \%, 23.4 \%$ and $20.7 \%$ respectively (Fig. 5). It was observed that there was a significant $(p<0.05)$ reduction in percentage release of ALT, AST and LDH after treatment with AEQ at a concentration of $2 \mathrm{mg} / \mathrm{ml}$ (Fig. 5). The percentage release of the liver enzymes from the liver tissue coexposed with ethanol and the plant extract $(2 \mathrm{mg} / \mathrm{ml})$ were markedly reduced and the values were $51.3 \%$, $54.4 \%$ and $37.6 \%$ for ALT, AST and LDH respectively. This confirms the protective effect of AEQ caused against ethanol induced liver damage.

Free radicals generated on ethanol consumption increases the cellular oxidative stress and results in damages to various cellular components eventually forming products such as lipoperoxides, conjugated dienes and malondialdehyde (MDA). This results in simultaneous reduction of endogenous antioxidant levels such as vitamin E, glutathione, superoxide dismutase, glutathione reductase etc. in tissues [32, 33]. Treatment of liver tissue with ethanol caused significant increase in the amount of lipid peroxides generated $(p<0.05)$ compared to the negative control (Fig. 6). However it was observed that the lipid peroxides formed in the ethanol treated liver slices were significantly $(p<0.05)$ reduced by AEQ at a concentration of $2 \mu \mathrm{g} / \mathrm{ml}$ (Fig. 6). The values for lipid peroxides in the negative control, ethanol induced liver toxicity and treated with plant extract in ethanol induced toxicity were $390 \pm 68,1496 \pm 545$ and $594 \pm$

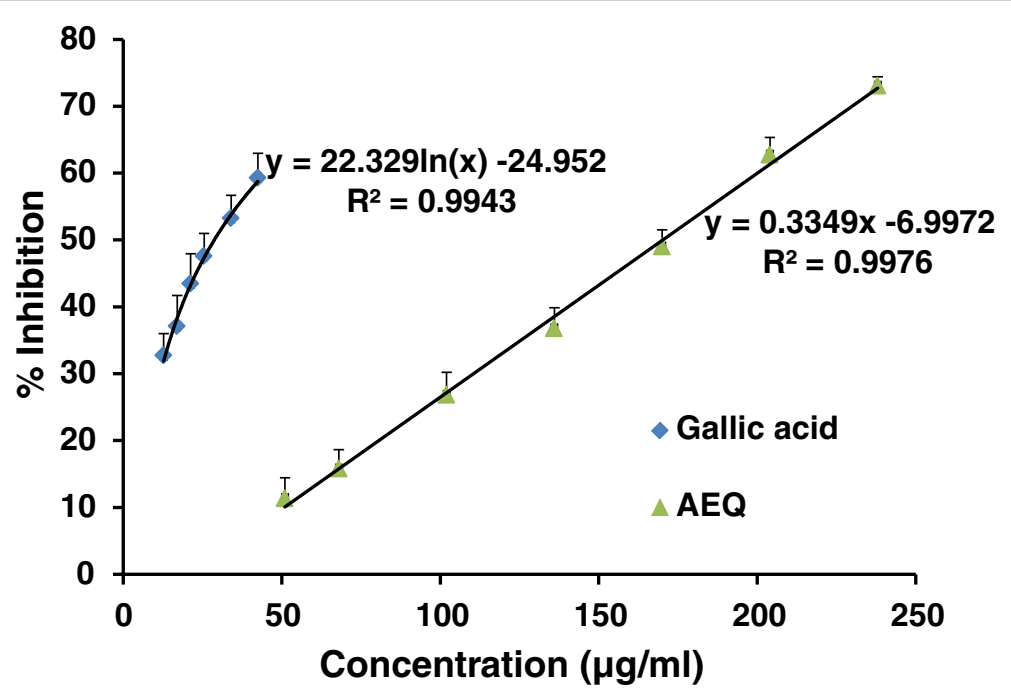

Fig 2 The dose response curves for percentage scavenging of hydroxyl radicals by AEQ in comparison with Gallic acid. The results are presented as mean + SD for AEQ $(n=3)$ and Gallic acid $(n=9)$ 

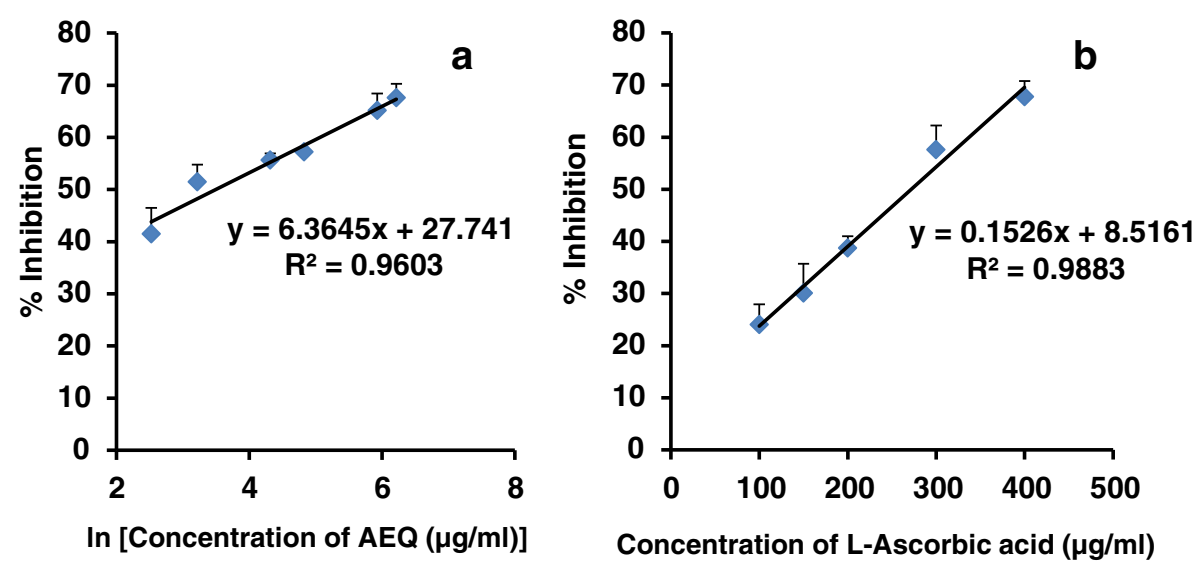

Fig 3 The dose response curve for percentage inhibition of NO radicals by AEQ (a) and L-Ascorbic acid (b). A linear relationship was observed between $\%$ I versus natural logarithm of concentration of AEQ. The results are presented as mean + SD of three independent experiments

$115 \mu \mathrm{g}$ MDA equivalents/g of protein respectively (Fig. 6). These results show that phytoconstituents present in AEQ have been able to scavenge lipid peroxides generated from 1-hydroxyethyl radical, an oxidative product of ethanol. AEQ possessing potent antioxidant capacity as evident by the DPPH, NO, Hydroxyl radical scavenging and FRAP assays undoubtedly has led towards preventing the formation of such oxidative products. The plant extracts alone in KRHB did not show any toxicity on liver tissue over the concentrations we studied. In a recent study carried out by Nazari and coauthors (2015), it has been found that ethanolic root extract of Taraxacum Syriacum Boiss can exert hepatoprotective activity against liver toxicity induced by acetaminophen (APAP) intoxication in rats
[34]. The authors believe that the mechanism through which the extract protects the liver from the oxidative stress caused by APAP is due to its antioxidant activity. It was suggested that the phenolic compounds present in the extract are responsible to exert the antioxidant mechanism through scavenging several reactive oxygen species. Such inferences can be made on the hepatoprotection caused by AEQ along with its high phenolic composition.

\section{Membrane stabilization activity}

The erythrocyte membrane is analogous to the lysosomal membrane [18]. A plant extract which stabilizes the lysosomal membrane suggests that it limits the release of lysosomal enzymes from lysosomes in activated

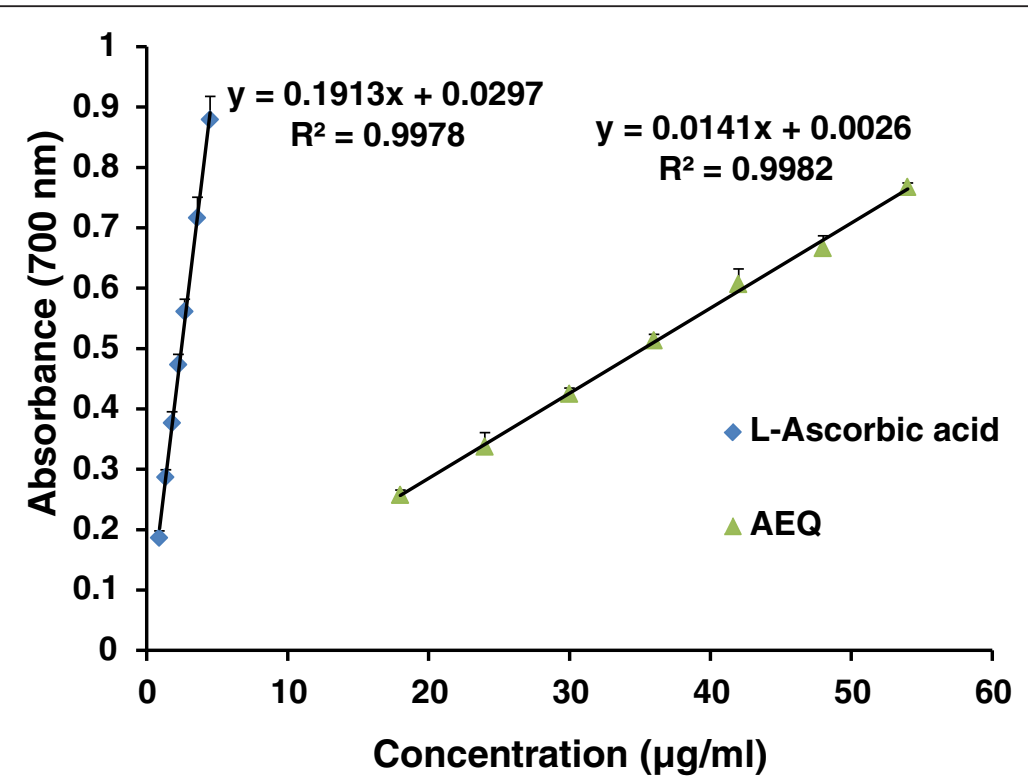

Fig 4 The reduction capability of different concentrations of AEQ compared to L-Ascorbic acid. The results are presented as mean + SD for AEQ $(n=3)$ and L-Ascorbic acid $(n=9)$ 


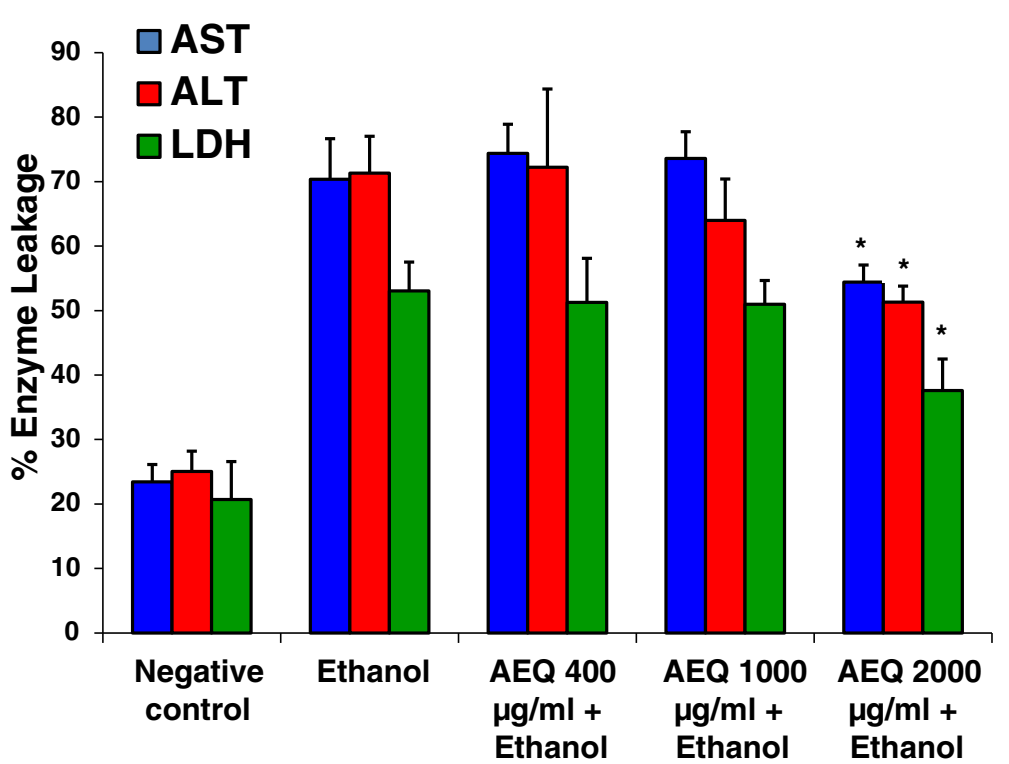

Fig 5 Percentage enzyme leakage of porcine liver slices after $2 \mathrm{~h}$ exposure (at $37^{\circ} \mathrm{C}$ ) to medium (negative control), ethanol and different concentrations of AEQ $(400,1000,2000 \mu \mathrm{g} / \mathrm{ml})$ with ethanol. Each value represents mean $+\mathrm{SD}(n=3){ }^{*} p<0.05$ when compared to ethanol treated sample with respect to the enzyme assayed. AST = Aspartate transaminase, ALT = Alanine transaminase, LDH = Lactate dehydrogenase

neutrophils into the surrounding tissue. The non steroidal drugs act either by inhibiting these lysosomal enzymes or by stabilizing the lysosomal membrane [18]. The $\mathrm{IC}_{50}$ values obtained in HEHA were $1.79 \pm 0.04 \mathrm{mg} / \mathrm{ml}$ and $2.55 \pm 0.08 \mathrm{mg} / \mathrm{ml}$ for AEQ and sodium salicylate respectively. This suggests the ability of AEQ to prevent hypotonic solution induced human erythrocyte membrane rupture is higher with respect to sodium salicylate. The dose response curves for the plant extract and sodium salicylate are illustrated in Fig. 7. Antioxidants possess profound ability to prevent the generation of ROS/RNS and enhance the resistance of biological target towards its attack [35]. This might be a possible reason for the suppression of the leakage of intracellular enzymes from liver tissue in addition to the membrane stabilizing activity induced by the phytochemicals present in AEQ. A research study was carried out recently by Shameela and coauthors (2015) to determine hepatoprotective activity of ethanolic

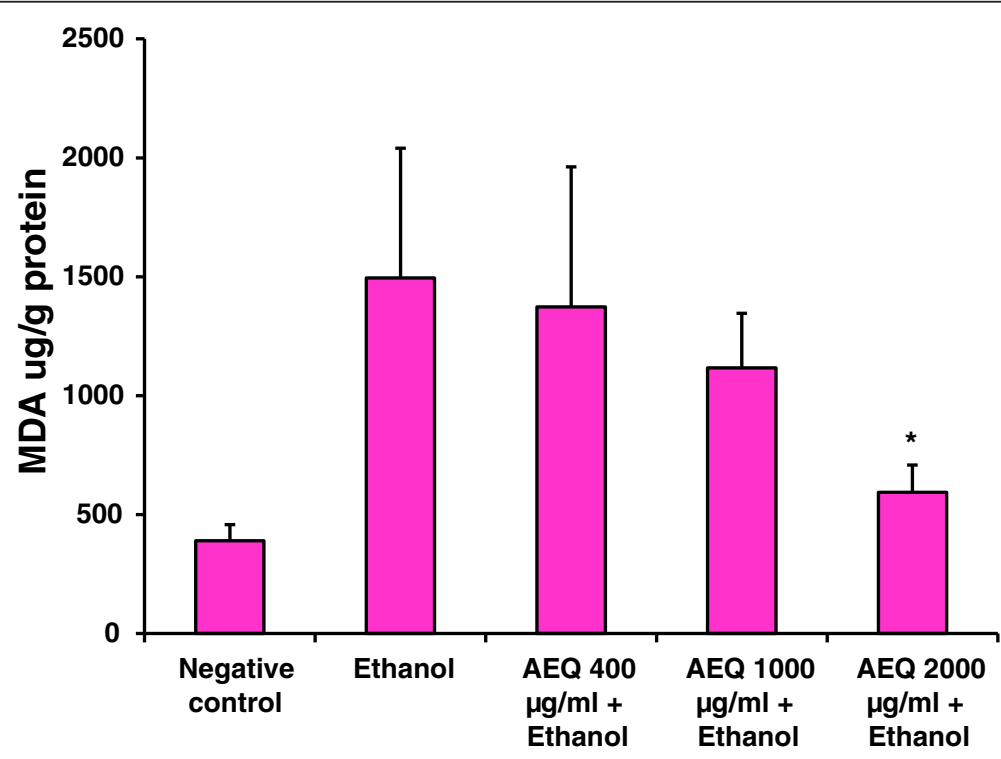

Fig 6 MDA equivalents formed in liver tissue homogenates after exposure to different conditions for $2 \mathrm{~h}$ incubation at $37^{\circ} \mathrm{C}$. Each value represents mean $+\mathrm{SD}(n=3) .{ }^{*} p<0.05$ when compared to ethanol $(5 \mathrm{M})$ treated sample. MDA = Malondialdehyde 


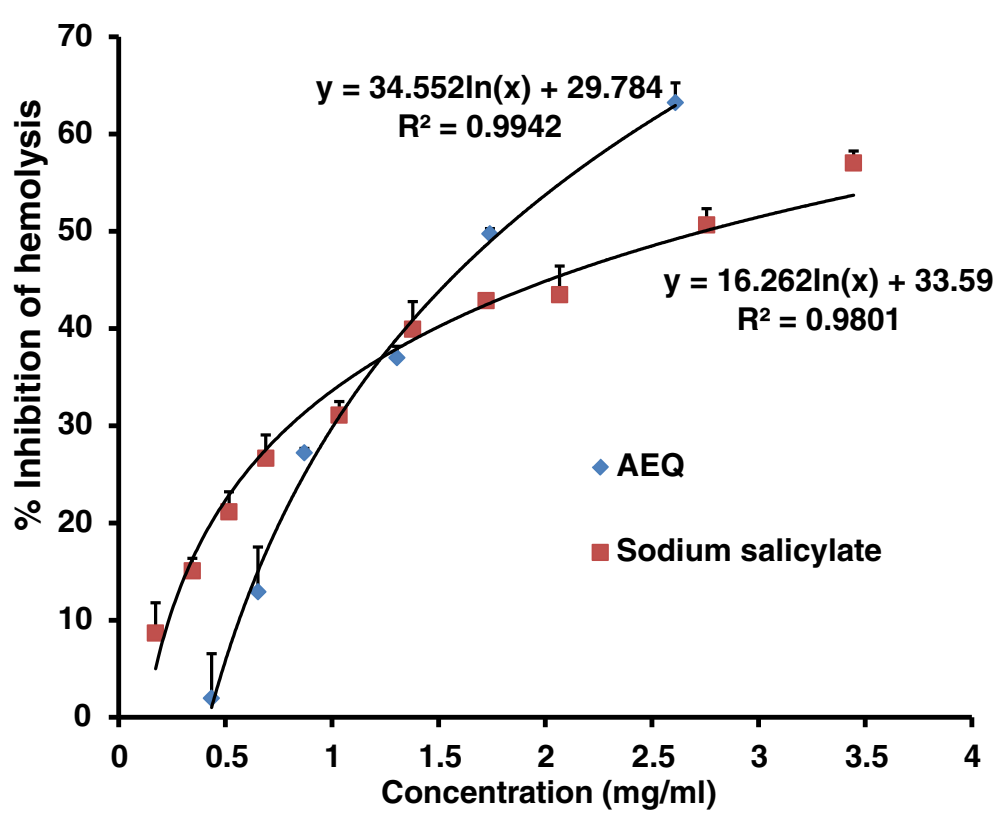

Fig 7 The dose response curves for percentage inhibition of hemolysis by AEQ and sodium salicylate. The results are presented as mean + SD of three independent experiments

extract of the whole plant of Boerhaavia diffusa against hepatitis induced by the administration of isoproterenol in Wistar rats [36]. The authors conclude that two possible reasons for the overall hepatoprotective effect of $B$. diffusa is due to a counteraction of free radicals by its antioxidant property or by its membrane stabilizing which helps to protect hepatocellular membrane against oxidative damages. Therefore similar deduction can be made of the potent antioxidants abundant in AEQ and its inherent membrane stabilizing effect.

\section{Conclusion}

Our findings suggest that the decoction prepared from $E$. quinquangulare has the potential to act as a strong antioxidant, hepatoprotective and a membrane stabilization agent. Mechanisms of membrane stabilization and free radical scavenging activity most possibly may contribute towards potent hepatoprotective activity possessed by the plant extract hence justifying its application in traditional medicinal system in Sri Lanka to treat liver ailments. However, further in vivo work including clinical trials is required to determine the synergistic and holistic effect caused by this decoction on the body.

\section{Additional file}

Additional file 1: IACUC Principles and Procedures of Animal Care and Use. (PDF $270 \mathrm{~kb}$ )

Competing interests

The authors declare that they have no competing interests.

\section{Authors' contributions}

Experimental work, analysis of data and drafting of the manuscript were carried out by CDF. PS contributed through designing the project, data interpretation and revising the manuscript for intellectual content. Both authors read and approved the final manuscript.

\section{Acknowledgements}

The authors acknowledge the financial assistance by National Science Foundation Sri Lanka and Department of Biochemistry \& Molecular Biology, Faculty of Medicine, University of Colombo. Special thanks go to Ms. Sudeepa Sugathadasa and Ms. Pushpa Jeewandara, Department of Botany, Bandaranayake Memorial Ayurvedic Research Institute, Nawinna, Sri Lanka, for the identification of the plant material. We particularly thank Technical staff of Department of Biochemistry \& Molecular Biology, Faculty of

Medicine, University of Colombo, for the assistance provided.

\section{Author details}

'Department of Biochemistry \& Molecular Biology, Faculty of Medicine, University of Colombo, Kynsey Road, Colombo 08, Sri Lanka. ${ }^{2}$ College of Chemical Sciences, Institute of Chemistry Ceylon, 341/22, Kotte

RoadWelikada, Rajagiriya, Sri Lanka.

Received: 24 September 2015 Accepted: 12 February 2016

Published online: 24 February 2016

\section{References}

1. Meera R, Devi P, Kameswari B, Madhumitha B, Merlin NJ. Antioxidant and hepatoprotective activites of Ocimum basilicum Linn. and Trigonella foenumgraecum Linn. against $\mathrm{H}_{2} \mathrm{O}_{2}$ and $\mathrm{CCl}_{4}$ induced hepatotoxicity in goat liver. Indian J Exp Biol. 2009;47:584-90.

2. Manzo-Avalos S, Saavedra-Molina A. Cellular and mitochondrial effects of alcohol consumption. Int J Environ Res Public Health. 2010;7(12):4281-304.

3. Hassan HMM. Hepatoprotective effect of red grape seed extracts against ethanol-induced cytotoxicity. Global J Biotechnol Biochem. 2012;7(2):30-7.

4. Albano E. Alcohol, oxidative stress and free radical damage. Proc Nutr Soc 2006;65(3):278-90. doi:10.1079/PNS2006496

5. Srivastava A, Shivanandappa T. Hepatoprotective effect of the aqueous extract of the roots of Decalepis hamiltonii against ethanol induced oxidative stress in rats. Hepatol Res. 2006;35(4):267-75.

6. Momin A. Role of indigenous medicine in primary health care. New Delhi, India: 1st International Seminar on Unani Medicine; 1987. p. 54. 
7. Dassanayake MD, Clayton WD. A Revised Handbook to the Flora of Ceylon Vol. 11. Rotterdam: A. A. Blakema; 1997. p. 383-6.

8. Ediriweera ERHSS. A Review on medicinal uses of weeds in Sri Lanka. Trop Agric Res Ext. 2007;10.

9. Perera MGAN, Soysa SSSBDP, Abeytunga DTU, Ramesh R. Antioxidant and cytotoxic properties of three traditional decoctions used for the treatment of cancer in Sri Lanka. Pharmacogn Mag. 2008;4(15):172-81.

10. Ugochukwu SC, Uche A, Ifeanyi O. Preliminary phytochemical screening of different solvent extracts of stem bark and roots of Dennetia tripetala $\mathrm{G}$. Baker. Asian J Plant Sci Res. 2013;3(3):10-3.

11. Ghasemzadeh A, Jaafar HZ, Rahmat A. Phytochemical constituents and biological activities of different extracts of Strobilanthes crispus (L.) Bremek leaves grown in different locations of Malaysia. BMC Complement Altern Med. 2015;15(1):422.

12. Halliwell B, Gutteridge JM, Arnoma OL. The deoxyribose method: a simple test tube assay for the determination of rate constant for reaction of hydroxyl radical. Anal Biochem. 1987;165:215.

13. Garret D. The quantitative analysis of drugs. Champman and Hall, Japan. 1964;3:456-8.

14. Oyaizu M. Studies on products of browning reactions: antioxidative activities of products of browning reaction prepared from glucosamine. Japanese J Nutr. 1986;44:307-15.

15. Fernando CD, Soysa P. Total phenolic, flavonoid contents, in-vitro antioxidant activities and hepatoprotective effect of aqueous leaf extract of Atalantia ceylanica. BMC Complement Altern Med. 2014;14:395.

16. Lowry OH, Rosebrough NJ, Farr AL, Randall RJ. Protein measurement with the Folin phenol reagent. J Biol Chem. 1951;193:265.

17. Lynch SM, Frei B. Mechanisms of copper- and iron dependent oxidative modification of human low-density lipoprotein. J Lipid Res. 1993;34: 1745-51.

18. Sadique J, Al-Rqobahs WA, Bughaith, El-Gindi AR. The bioactivity of certain medicinal plants on the stabilization of RBS membrane system. Fitoterapia. 1989;60:525-32

19. Al-Sayed E, Martiskainen O, SH S e-D, Sabra ANA, Hammam OA, El-Lakkany NM, et al. Hepatoprotective and Antioxidant Effect of Bauhinia hookeri Extract against Carbon Tetrachloride-Induced Hepatotoxicity in Mice and Characterization of Its Bioactive Compounds by HPLC-PDA-ESI-MS/MS. BioMed Res Int. 2014;2014:1-9.

20. Ho YL, Huang SS, Deng JS, Lin YH, Chang YS, Huang GJ. In vitro antioxidant properties and total phenolic contents of wetland medicinal plants in Taiwan. Bot Stud. 2012;53:55-66.

21. Tapas AR, Sakarkar DM, Kakde RB. Flavonoids as nutraceuticals: a review. Trop J Pharm Res. 2008;7:1089-99.

22. Weidinger A, Kozlov AV. Biological activities of reactive oxygen and nitrogen species: oxidative stress versus signal transduction. Biomolecules. 2015;5:472-84.

23. Molyneux $\mathrm{P}$. The use of the stable free radical diphenylpicrylhydrazyl (DPPH) for estimating antioxidant activity Songklanakarin. J Sci Technol. 2004;26(2):211-9.

24. Harput US, Genç Y, Khan N, Saracoglu I. Radical scavenging effects of different Veronica Species. Rec Nat Prod. 2011;5(2):100-7.

25. Jagetia GC, Rao SK, Baliga MS, Babu KS. The evaluation of nitric oxide scavenging activity of certain herbal formulations in vitro: a preliminary study. Phytother Res. 2004;18:561-5.

26. Yen GC, Chen HY. Antioxidant activity of various tea extracts in relation to their antimutagenicity. J Agric Food Chem. 1995;43:27-32.

27. Grosse-Siestrup C, Pfeffer J, Unger V, Nagel S, Witt C, Fischer A, Groneberg DA. Isolated hemoperfused slaughterhouse livers as a valid model to study hepatotoxicity. Toxicol Pathol. 2002;30:749.

28. Naik RS, Mujumdar AM, Ghaskadbi S. Protection of liver cells from ethano cytotoxicity by curcumin in liver slice culture in vitro. J Ethnopharmacol. 2004;95:31-7.

29. Mahnaaz M, Swati K, Devasagayam TP, Saroj G. Pterocarpus marsupium extract reveals strong in vitro antioxidant activity. Drug Discov Ther. 2009:3:151-61.

30. Vilei MT, Granato A, Ferraresso C, Neri D, Carraro P, Gerunda G, Muraca M. Comparison of pig, human and rat hepatocytes as a source of liver specific metabolic functions in culture systems-implications for use in bioartificial liver devices. Int J Artif Organs. 2001;24(6):392-6.

31. Saraswat B, Visen PK, Patnaik GK, Dhawan BN. Anticholestic effect of picroliv, active hepatoprotective principle of Picrorhiza kurroa against carbon tetrachloride induced cholestatis. Indian J Exp Biol. 1993;31:316-8.
32. Christina AJ, Saraswathy GR, Robert SJ, Kothai R, Chidambaranathan N, Nalini $\mathrm{G}$, et al. Inhibition of $\mathrm{CCl}_{4}$-induced liver fibrosis by Piper longum Linn. Phytomedicine. 2006;13:196-8.

33. Pal R, Nath R, Gill KD. Lipid peroxidation and antioxidant defense enzymes in various regions of adult rat brain after coexposure to cadmium and ethanol. Pharmacol Toxicol. 1993;73:209-14.

34. Nazari A, Fanaei H, Dehpour AR, Hassanzadeh G, Jafari M, Salehi M, Mohammadi M. Chemical composition and hepatoprotective activity of ethanolic root extract of Taraxacum Syriacum Boiss against acetaminophen intoxication in rats. Bratisl Lek Listy. 2015;116(1):41-6.

35. Habibi E, Shokrzadeh M, Chabra A, Naghshvar F, Keshavarz-Maleki R, Ahmadi A Protective effects of Origanum vulgare ethanol extract against cyclophosphamide-induced liver toxicity in mice. Pharm Biol. 2014;53(1):10-5.

36. Shameela S, Shamshad S, Indira Priyadarsini A, Lakshmi Devi K. Evaluation of Boerhaavia diffusa for hepatoprotective activity in experimental Wistar rats. Int J Pharm Biol Sci. 2015;5(1):115-22.

\section{Submit your next manuscript to BioMed Central and we will help you at every step:}

- We accept pre-submission inquiries

- Our selector tool helps you to find the most relevant journal

- We provide round the clock customer support

- Convenient online submission

- Thorough peer review

- Inclusion in PubMed and all major indexing services

- Maximum visibility for your research

Submit your manuscript at www.biomedcentral.com/submit
) Biomed Central 